\title{
Celso Sánchez Capdequí (ed.). Creatividad: entre transgresión y normalización. Madrid: La Catarata, 2020
}

Pablo Echeverría

Universidad Pública de Navarra, España

echeverriapablo94@gmail.com

La creatividad parece haberse constituido como lugar común en buena parte de los discursos actualmente predominantes. Bien sea como parte de una reacción pendular a escenarios previos, focalizados en una imagen funcional-racionalista del ser humano y sus relaciones, bien como desbordamiento de estos - por ejemplo a través de la terminología y el imaginario de la innovación -, o - más probablemente - simultaneándo y entremezclándose ambos supuestos, la referencia a lo creativo ha pasado de ser reivindicación transgresora a excurso altamente normativizado. Es este proceso el que, ya desde su título - Creatividad: entre transgresión y normalización -, se presenta y analiza lúcidamente en esta obra, recuperando además algunas de las implicaciones y resonancias de un concepto que, en - para y por - su normativización, se ha visto mutilado, simplificado y constreñido.

En un contexto tardomoderno caracterizado por la falta de estabilidad y certidumbre, cobran gran relevancia dos cuestiones íntimamente ligadas, tanto entre sí, como al concepto de creatividad. Una de ellas, universalizable a toda forma de lo social. La segunda, mucho más específica y conectada a nuestra realidad concreta.

La primera es su condición de concepto clave en las relaciones entre el ser humano y su entorno - incluyendo aquí al resto de sujetos -, así como en la concepción de estas. La idea de una construcción social de la realidad supone en sí misma la implicación directa de la creatividad en los constantes procesos de (re)articulación de la experiencia y en la creación de un universo simbólico, lo cual da a su vez - como tampoco pasaron por alto Berger y Luckmann - un papel de gran relevancia al lenguaje. Esto la dota de una ambivalencia previamente insinuada, en la medida en que es parte tan indispensable de los procesos tendentes al orden social, como de aquellos más propensos a generar desorden. También las reacciones a y la comprensión de todo aquello que - merced a la sensibilidad y tino con que es tratado en el cuarto capítulo del libro - podemos llamar caos, azar, Apeiron, fortuna, indeterminación, riesgo o contingencia; se ve indefectiblemente atravesado por un fuerte componente creativo. No obstante, y siendo fundamental en ello la noción de trascendencia, tal y como es abordado por los autores, esta es una de las aristas de la creatividad menos atendidas en el momento actual.

Ello, como hemos adelantado, nos conecta con la segunda cuestión. Nos hallamos en un escenario no solo de aumento de la incertidumbre, sino también del grado de percepción de la misma, al debilitarse - sin desaparecer - una sensación de control sobre el entorno alimentada en etapas previas. Esta coexistencia entre lo desconocido conocido y lo desconocido desconocido coloca al ser humano en una posición y una dinámica sustantivamente novedosa en lo relativo a su relación con sus circunstancias vitales. Se cuestiona súbita y contundentemente una narrativa hasta entonces dominante. Aquella que alude a un tránsito lineal, evolutivo y unidireccional entre el mythos y el logos, así 
como entre lo religioso y lo secular. El ser humano ya no se percibe a sí mismo como parte de un orden natural inalterable, preconcebido y frente al cual actúa únicamente como variable dependiente, pero tampoco - o no solo - prevalece la idea de una humanidad cuasiomnisciente y cuya capacidad de control técnico-racional sobre los elementos le permite conocer y gestionar a su antojo el mundo que le rodea. Se trata de una fase histórica en la que ostentamos un mayor conocimiento de nuestro desconocimiento, lo cual nos hace a un tiempo rotundamente poderosos y vulnerables. No obstante, parece inevitable percibirse más bien como lo segundo, tales son los desconocimientos - y los riesgos, si acudimos a Beck - actualmente cognoscibles. Dicho de otra manera, el crecimiento de nuestras posibilidades de actuación sobre el entorno parece aumentar y consolidar más bien nuestra capacidad para amenazarnos que para protegernos.

Más allá de estas dos cuestiones directamente asociadas a la creatividad, podemos hablar de manifestaciones concretas de la misma, asociadas a dinámicas de priorización de lo (relativamente) nuevo - carente de ruptura estructural alguna y con especial énfasisis en lo estético -, las pequeñas trascendencias y una efervescencia de escaso alcance y eco. En contraposición con la ilusión de plenipotenciareidad - pero sin que esta termine de retirarse, como demuestra la fuerza adquirida por los discursos del éxito personal asociados por ejemplo al neomanagement o el coaching -, la impotencia, el fracaso y el vacío inundan el sentir humano. La aceleración social ahonda en estos aspectos, generando el vértigo de saber que cualquier paso en falso nos rezaga. No existen asideros reales, ya que aquello que puede asirse con frecuencia resulta no estar a su vez sujeto a nada. Tal es la condición líquida - incluso gaseosa, como ya hay quien sugiere - de nuestra época y de la cual emerge cierta tiranía del presente y una autorreferencialidad rallante en lo compulsivo. Frente a la aceleración no se busca deceleración, sino retención de instantes y experiencias concretas. En el actual dispositivo de la creatividad (Reckwitz) la abstracción y la interrelación de espacios, tiempos y vivencias pierden peso en favor de lo experienciable, preferiblemente capturable y encapsulado - por tanto necesaria e inevitablemente desconectado de lo demás y de las medianas y grandes trascendencias -. Ante la imposibilidad de lograr algo permantente o duradero en el vacío de trascendencias, sentidos, narrativas y legados; se recurre al yo y al ahora - en forma de triunfos autorreferenciales socialmente valorados, encapsulables y exhibibles - como lo único disponible. El turismo de lo culturalmente exótico - apropiado mediante la imagen virtualmente inmortalizada y en la idea de <<tener mundo»>-, o la (auto)superación a través del deporte numéricamente registrado en forma de rendimiento - mostrable vía redes sociales - resaltan como ejemplos cotidianos y generalizados de un fetichismo de la huella cuya vertiente individualizada se instaura en el concepto de identidad. Se compite por una imagen de éxito (no) perecedera que, en un contexto de aceleración y volatilidad, pueda evidenciar ante el mundo nuestra prolificidad experiencial y retener tal evidencia como factor clave para la construcción de una narrativa sobre el yo que nos constituye, posiciona y jerarquiza socialmente.

En la renuncia parcial, probablemente involuntaria e/o inconsciente a la trascendencia que va implícita en este proceso, pasa a sacralizarse el mero énfasis. La experiencia es valorada por su potencia y frecuencia, esperándose una permanente afluencia de experiencias estéticamente novedosas que, además, no solo es socialmente premiada, sino exigida. Exigencia cuyo carácter constante y universalizado la hace inalcanzable en sí misma, dada limitación de los recursos - incluyamos aquí la atención del público numeralizada mediante visitas, likes, etc - existentes para ello. El imperativo creativo resulta por tanto, desde sus propias premisas, tan irrealizable como obligatorio. Es precisamente el ethos cotidiano de una exitosa forma de vida creativa lo que lleva de forma inevitable al fracaso de la mayoría social.

Es así como Eros, en las consecuencias - y producto(s) - de su influjo dinamizador, profundiza en la volatilidad y fugacidad propias de la tardomodernidad, al tiempo que las 
cuestiona al erigirse como principio rector fundamental - inestable y coexistente con otros, pero difícilmente sustituible - de la acción social. Se instaura la multiplicidad de relaciones tangenciales, efímeras y volátiles, que ponen en contacto superficial y momentáneo a los actores, tanto entre sí como con los objetos. Tal lógica también rige en una esfera económica centrada en la producción, distribución y consumo de objetos y servicios semiótico-estéticos. Una industria cultural ya apuntada por Adorno y Horkheimer cuyos productos, abundando en tal término, no son únicamente mercancías - aún incluyendo su concepción inmaterial como mercancía cultural -, sino también subjetividades concretas asociadas a las prácticas representadas en ellos e implícitamente valoradas como positivas por los imaginarios y discursos que las subyacen. No se trata por tanto de una producción meramente vacía - en lo referente a determinados planos de trascendencia -, sino que desde la aparente singularidad de lo novedoso fomenta tales vacíos y carencias, contribuyendo a la perpetuación de las dinámicas descritas.

Como vemos, y aunque en ocasiones pueda presentarse como tal por los términos y evocaciones que emplea, el dispositivo de la creatividad no es en absoluto pueril, frívolo o fútil, como tampoco lo son sus efectos y manifestaciones. Entraña procesos de subjetivacion, trayectorias vitales, modelos sociales y políticos y narrativas del mundo concretas, que se imponen a otras y cuyas consecuencias - en especial las negativas deben ser puestas sobre la mesa.

Esta es la tarea abordada en un libro que, para ello, se estructura en dos partes claramente diferenciadas. Aunque ambas aluden a las formas concretas de la creatividad actualmente dominantes y normativizadas, lo hacen mediante aproximaciones diversas. La primera desmenuza la propia idea de creatividad, sus transformaciones y usos históricos, los papeles, configuraciones y fisionomías que puede tomar; hasta llegar a las que de hecho toma de forma predominante en las sociedades tardomodernas. La segunda escudriña en estas fisionomías, tomando casos más específicos de sus manifestaciones para someterlos a análisis cuyas conclusiones dan muestra de la complejidad de lo estudiado, al constatar tanto lo planteado en los capítulos previos, como la existencia de resistencias y formas contraculturales a estas manifestaciones hegemónicas de la creatividad. Es precisamente esta coexistencia, la sincronicidad de las desincronicidades entre el régimen ya consolidado de la novedad estética, el régimen de la novedad en la innovación y los regímenes de la repetición ya existentes o nuevamente movilizados lo que queda demostrado y situado como objeto de estudio fundamental para una sociología de la creatividad correctamente enfocada.

Se trata en suma de un ejercicio de reflexión heterogéneo aunque altamente coordinado, convergente y complementario en lo referente a los prismas tomados; cuyas conclusiones resultan imprescindibles para la comprensión de nuestra época, a la par que nos sitúan ante la extrema dificultad que tal pretensión lleva implícita. Dos labores de gran valor en sí mismas, pero cuya armonización retroalimenta sus respectivos méritos. 
